\title{
Dental fluorosis severity in children $8-12$ years old and associated factors
}

\author{
Alexandra Saldarriaga ${ }^{1,2}$, Diego Rojas-Gualdrón³, Manuel Restrepo², Lourdes \\ Santos-Pinto 4 , Fabiano Jeremias ${ }^{1}$
}

1. Universidade Estadual Paulista, São Paulo, Facultad de Odontologia de Araraquara, Programa de Pos-Graduación em Ciências Odontológicas, Araraquara-SP, Brasil

2. Universidad CES, Facultad de Odontología, Departamento de investigación, Medellín, Colombia

3. Universidad CES, Facultad de Medicina, Departamento de investigación., Medellín, Colombia

4. Universidade Estadual Paulista, São Paulo, Facultad de Odontologia de Araraquara, Departamento de Morfologia e

Odontopediatria, Araraquara-SP Brasil.

\begin{abstract}
The aim of this study was to determine the frequency and severity of dental fluorosis (DF) and the association between severity and risk factors. In a cross-sectional study, 8- to 12-year-old children, born in a Colombian district, were evaluated according to the Thylstrup and Fejerskov Index (TFI) by two calibrated examiners. Molar Incisor Hypomineralization (MIH) and dental caries (DC) were also evaluated. Ordinal logistic regression was applied $(p<0.05)$. Risk factors and lifestyle factors were collected using a questionnaire answered by parents. DF was detected in 76 (98.7\%) of the children (average of $18.4 \pm 1.81$ permanent teeth affected). Grade TF2 was the most frequently observed (34.8\%); TF5 was observed in all age groups; TF6TF7 were observed in 12-year-olds. No association was found
\end{abstract}

between DF severity and DC (Odds Ratio $(O R)=1.35$; $95 \% C I$ : 0.56-3.26) or $\mathrm{MIH}(\mathrm{OR}=1.39$; 95\%CI: 0.43-4.46). DF severity was significantly associated with use of an indoor wood stove for food preparation $(O R=9.34 ; 95 \% C I: 1.11-78.57)$ and use of a pea-sized volume of toothpaste $(O R=27.42 ; 95 \%$ CI: 1.57-477.36). Prevalence of DC was $38.1 \%$ and prevalence of MIH was $14.4 \%$. In this population, the frequency of $D F$ was high and severity was associated with use of an indoor wood stove for food preparation and toothpaste amount used during childhood.

Received: March 2021; Accepted: May 2021.

Keywords: dental fluorosis - severity - children.

\section{Severidad de fluorosis dental y factores asociados en niños de 8-12 años de edad}

\begin{abstract}
RESUMEN
El objetivo de este estudio fue determinar la prevalencia y severidad de la Fluorosis Dental (FD) y la asociación de la severidad con factores de riesgo. Mediante un estudio transversal, niños (8-12 años-de-edad), nacidos en Ayapel (El Cedro-Colombia) fueron evaluados por 2 examinadores calibrados, según los criterios del indice de Thylstrup y Fejerskov (TFI) para FD. También se evaluaron la Hipomineralización molar-incisiva (HMI) y la caries dental (CD). Se aplicó un cuestionario de factores de riesgo y estilo de vida, a los padres/responsables de los niños. Se utilizó un modelo de regresión logística ordinal $(p<0.05)$. Se encontró FD en 76 (98.7\%) niños (con una media de dientes permanentes afectados de $18.4 \pm 1.81)$. La severidad categoría TF2 fue la más observada (34.8\%) en los dientes evaluados. Las lesiones que presentan pérdida estructural moderada TF
\end{abstract}

6-7, fueron evidenciadas en el grupo de edad de 12 años. No se encontró asociación entre la severidad y la $C D(O R=1.35$; IC95\%:0.56-3.26) o con HIM (OR=1.39; IC95\%:0.43-4.46). Se encontró una asociación significativa con la severidad de la FD en los niños que utilizaban fogón de leña-interno para la preparación de los alimentos $(O R=9.34$; IC95\%:1.11-78.57) y utilizaban un volumen de crema dental del tamaño de una alverja-pequeña $(O R=27.42$; IC95\%:1.57-477.36). la prevalencia de CD fue $38.1 \%$ y de HMI fue $14.4 \%$. La frecuencia de la FD fue alta y la severidad mostró correlación con la utilización de fogón de leña interno para la preparación de los alimentos y la cantidad de crema-dental utilizada.

Palabras clave: fluorosis dental - severidad - niños. 


\section{INTRODUCTION}

Dental fluorosis (DF) is an endemic disease in various parts of the world ${ }^{1-3}$. Its etiology is directly related to an increased total amount of fluoride $(F)$ ingested from various sources during the amelogenesis period $^{4,5}$. Multiple sources of $F$ have the potential to cause $\mathrm{DF}$, including natural $\mathrm{F}$, artificial $\mathrm{F}$ or $\mathrm{F}$ added to water, dental products, cooking salt, milk and dietary supplements, and exposures related to occupation or lifestyle. However, the intake of $F$ in water is considered to be the main cause of $\mathrm{DF}^{5-7}$.

There are other forms of DF in which other factors are involved; for example, in China, foods such as tea, corn, and chili cooked for a long time and at high temperatures in coal and mud stoves have been associated with $\mathrm{DF}^{1,3,8-10}$. Other parts of the world, such as India $(64.3 \%)^{11}$, Nigeria $(26.1-51.0 \%)^{12}$, Mexico $(83.8 \%)^{13}$ and Brazil $(8.53-80.4 \%)^{14}$, have low normal concentrations of $\mathrm{F}$ in water, but high prevalence of DF due to the artificial addition of $\mathrm{F}$ to the water. Other associated factors include the frequency of tooth brushing, the time elapsed between the emergence of the first tooth and the use of toothpaste ${ }^{15,16}$ and $\mathrm{F}$ added to common topical agents ${ }^{4,9}$. The varying socioeconomic, environmental, hydrochemical, and individual factors lead to differences in $\mathrm{F}$ exposure across countries, regions, and districts, and therefore to different degrees of severity of Dental Fluorosis. The increasing use of $\mathrm{F}$ as a caries-preventive agent in populations with different degrees of exposure to $\mathrm{F}$ has sparked controversies regarding the riskbenefit and dosage of $\mathrm{F}$, which warrant further research. The clinical and epidemiological diagnosis of DF could be monitored in different scenarios and subgroups of specific endemic communities or individuals who share the same conditions, lifestyle, and social and environmental settings. The endemic characteristics provide indications for DF severity and its association with demographic factors, oral hygiene habits, and individual child-related factors ${ }^{17}$. It is important to identify all of the risk factors as well as to detect the disease early, chiefly during primary dentition, to prevent fluorosis in permanent dentition ${ }^{18}$. Thus, clinical detection of fluorosis, identification of its causes and differential diagnosis are essential for the clinical management of affected patients. Epidemiological knowledge of the disease is important for determining actions to promote oral health and may contribute to preventing it in future generations. The aim of the present study was to identify the presence of dental fluorosis among 8 - to 12-year-old children and establish its severity and association with dental caries (DC), Molar Incisor Hypomineralization (MIH), medical/dental history, and factors related to lifestyle, in an isolated rural community where there is concern about DF and its severity.

\section{MATERIAL AND METHODS}

This study was designed following the STROBE (Strengthening the Reporting of Observational Studies in Epidemiology) guidelines as a crosssectional study on a sample of 77 children aged 8 to 12 years in El Cedro (Northern Colombia). The population consisted of 929 inhabitants who have been covered since 1989 by the public health program in Colombia for the fluoridation of cooking salt (180-220 ppm). The area has an average water F concentration of $0.10 \mathrm{ppm}$, temperature $32.7^{\circ} \mathrm{C}$, elevation above sea level 40 meters. It receives water from a natural well, does not have a municipal aqueduct for water treatment, and also has river access. Data were collected in August 2018.

Subjects included in the study were 8- to 12-year-old children born in Ayapel in the El Cedro district, who had at least the first permanent molars and permanent upper and lower incisors erupted. Exclusion criteria were presence of syndromes linked to enamel malformations, dental enamel defects caused by trauma, and use of orthodontic appliances.

Among 220 children invited to participate in this study, 77 were examined. A total 143 children were not examined due to absence of permanent maxillary lateral incisors (12), not having parental informed consent (28) or absence from school on the examination day as a result of the geographic situation of the scattered population. The results are presented for 76 participants that had DF at the time of the clinical evaluation. Only one examined child did not present DF.

A post hoc power analysis determined that with a Type-I error rate $=5 \%$ and $40 \%$ controls exposed, the sample of 76 participants has statistical power $\geq 80 \%$ for $\mathrm{OR} \geq 2.3$ (or $\mathrm{OR} \leq 0.44$ ).

The clinical evaluations were performed in a dental office equipped with artificial light and a suction, water and air system, using a dental mirror and periodontal probe, as recommended by the World 
Health Organization (WHO). After cleaning and drying the teeth, the complete examination was conducted by two evaluators calibrated for the diagnosis of DF as primary outcome (intra-examiner kappa $=0.89$; inter-examiner kappa $=0.87$ ) according to the criteria proposed by Thylstrup and Fejerskov $(\mathrm{TFI})^{19}$. Molar incisor hypomineralization $(\mathrm{MIH})$ was diagnosed based on the criteria of the European Academy of Pediatric Dentistry (EAPD) ${ }^{20}$. Dental caries (DCs) in permanent teeth was evaluated using the DMFT index (decayed, missing, and filled teeth), following the WHO criteria ${ }^{21}$. Differential diagnosis with other non-fluorotic enamel opacities and white spots was based on the criteria proposed by $\mathrm{Seow}^{22}$ (Kappa> 0.85). For the inter-examiner calibration, 20 children from each age group were evaluated and 10 children were selected at random for intra-examiner calibration. The trained staff applied a semi-structured questionnaire to all children's parents or guardians to assess economic factors, oral hygiene habits, and other individual factors and environmental aspects, for evaluation of the secondary outcome.

\section{Ethical approval}

This study was previously approved by the Institutional Committee for Research Ethics in Human Beings of the CES University (Medellín, Colombia) (Certificate No. 110-Code 718). Parents signed consent to approve their children's participation. Children underwent psychological evaluation before parents signed the consent.

\section{Statistical analysis}

The data was processed in STATA program version $16^{\circledR}$ (College Station, TX). In the descriptive analysis, frequencies and percentages were used for categorical variables, while measures of central tendency and dispersion were used for quantitative variables. The results for DF are described according to Fejerskov et al..$^{23}$. The factors associated with DF severity were analyzed by ordinal logistic regression. DF severity according to TF categories (TFI 0-9) ${ }^{19}$ is an ordinal variable and was the response variable. We estimated crude Odds Ratios (OR) with simple regression models and adjusted OR with a multiple regression model. For adjustment estimations, variables with $\mathrm{p}<0.25$ were included using the enter method. OR are presented with $95 \% \mathrm{CI}$ and $\mathrm{p}$ values. According to the Hosmer-Lemeshow goodness-of- fit test for ordinal logistic regression, the multivariate model presented in the results showed a good fit to the data ( $\mathrm{p}=0.733$ ). Additionally, a PulkstenisRobinson test was performed for each variable to assess the assumption of proportionality of the Odds, obtaining positive results.

\section{RESULTS}

This study evaluated 77 children between 8 and 12 $(10.2 \pm 1.99)$ years of age in the El Cedro district. The prevalence of DF was $98.7 \%$. The analysis included only the 76 children with DF (TFI $\geq 1$ ). Distribution of the study population according to sex, age, TFI, DMFT, MIH, and other individual variables is presented in Table 1 . The prevalence of DC was $38.1 \%$. Mean DMFT was 0.82 (SD 1.27). The mean decay component was 0.38 (SD 0.81), and the filled component was 0.44 (SD 0.98). No statistically significant difference in the prevalence of DF was observed between boys and girls ( $\mathrm{p}=$ $0.33)$. In these children, the maximum TFI was TF7, with TF3 $(48.6 \%)$ being the most frequent, followed by TF2 $(22.3 \%)$.

Assessment of economic conditions revealed that $72.37 \%$ of the children's families did not receive a family income. The water used for food preparation was obtained through the faucet in their homes via a well (50\%), and $44.74 \%$ used an outdoor wood stove.

With regard to distribution of teeth affected by DF according to age and severity (TFI) ${ }^{23}$ (Table 2), TF1TF3 were the most commonly observed grades at the tooth level, most frequently TF2 (34.8\%). Lesions presenting TF5 loss of structure were observed in all age groups, while TF6-TF7 lesions were mainly seen in the teeth of children in the 12-year-old group. There was no association between increasing age and DF severity $(\mathrm{p} \geq 0.05)$. In this study, $18.4 \pm$ 1.81 permanent teeth were affected per child.

Fig. 1 shows the proportions of affected teeth for each child according to the TFI scale ${ }^{23}$. TF $\geq 1, \geq 2$, $\geq 3, \geq 4$, and $\geq 5$ were observed in $98.78 \%, 89.59 \%$, $68.47 \%, 19.76 \%$, and $17.11 \%$, respectively, of the children examined. Likewise, $82.96 \%$ and $17.13 \%$ of the children had, in at least $50 \%$ of their teeth, $\mathrm{TF} \geq 1$ and $\geq 3$ respectively, and $26 \%$ had $\mathrm{TF} \geq 5$ in $1.32 \%$ of their teeth.

According to type of tooth, TF1 diagnosis was the most common in the upper and lower central and lower lateral incisors. TF2 diagnosis was the most 
Table 1. Distribution of the characteristics of 8- to 12-year-old children with DF. El Cedro, Colombia, 2018

Variable

Sex

TF

Age (years)

DMFT

MIH

Start of brushing (age, years)

Toothbrushing (times per day)

Toothpaste amount

Toothpaste type

Swallows toothpaste

Milk type

Water source

Oven type

Family income
Male

Female

8

9

10

11

12

1

2

3

4

5

6

7

0

$\geq 1$

0

$>0$

$\leq 3$

$>3$

1

2

3

Minimum

Small layer

Pea-sized volume

More than pea-sized volume

Children's

Adult

Both

Yes

No

Mother's milk

Infant formula

Cow's milk

Aqueduct, untreated

Well

Electric

Gas

Indoor, wood-fired

Outdoor, wood-fired

No income

Minimum income $n(\%)$

37 (48.6)

39 (51.3)

11 (14.4)

17 (22.3)

12 (15.7)

17 (22.3)

19 (25.0)

7 (9.2)

17 (22.3)

37 (48.6)

2 (2.6)

$11(14.4)$

1(1.32)

1 (1.32)

47 (61.84)

29 (38.16)

65 (85.5)

11 (14.4)

50 (65.79)

26 (34.21)

25 (32.89)

35 (46.05)

16 (21.05)

3 (3.95)

25 (32.89)

35 (46.05)

13 (17.11)

34 (44.74)

$38(50.00)$

4 (5.26)

42 (55.26)

34 (44.73)

70 (92.11)

4 (5.26)

2 (2.64)

$38(50.0)$

$38(50.0)$

6 (7.89)

21 (27.63)

15 (19.75)

34 (44.74)

55 (72.37)

21 (27.64)

Abbreviations: TF, Thylstrup and Fejerskov criteria; DMFT, decayed, missing, and filled teeth; MIH, molar incisor hypomineralization 


\begin{tabular}{|c|c|c|c|c|c|c|c|}
\hline \multicolumn{8}{|c|}{ Classification of severity (Thylstrup and Fejerskov, 1988) (3. $^{23^{*}}$} \\
\hline \multirow[t]{2}{*}{ Age (years) } & TF1 & TF2 & TF3 & TF4 & TF5 & TF6 & TF7 \\
\hline & n (\%) & n (\%) & n (\%) & n (\%) & n (\%) & n (\%) & n (\%) \\
\hline 8 & $52(11.5)$ & $33(6.8)$ & $39(9.8)$ & $1(11.1)$ & $2(6.7)$ & - & - \\
\hline 9 & $89(19.6)$ & $77(15.8)$ & $60(15.0)$ & - & $13(43.3)$ & $1(8.3)$ & - \\
\hline 10 & $67(14.8)$ & 86 (17.7) & $68(17.0)$ & - & $1(3.3)$ & - & - \\
\hline 11 & $115(25.4)$ & $125(25.7)$ & 124 (31.1) & 1 (11.1) & $3(10.0)$ & - & - \\
\hline 12 & $130(28.7)$ & 165 (3.0) & $108(27.1)$ & $7(77.8)$ & $11(36.7)$ & $11(91.7)$ & $9(100.0)$ \\
\hline Total n(\%) & $453(32.4)$ & $486(34.8)$ & 399 (28.5) & $9(0.6)$ & $30(2.2)$ & $12(0.9)$ & $9(0.6)$ \\
\hline \multicolumn{8}{|c|}{$\begin{array}{l}\text { ”TF1: soft white lines. } \\
\text { TF2: small cloudy areas } \\
\text { TF3: hazy areas of opacity and white lines } \\
\text { TF4: entire surface has opacity (white limestone). } \\
\text { TF5: opaque surface with rounded depressions less }\end{array}$} \\
\hline
\end{tabular}

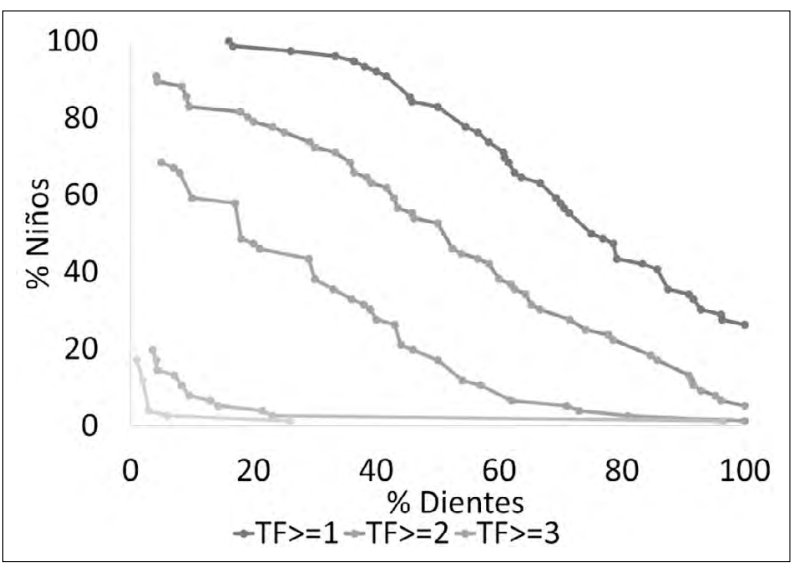

Fig. 1: Distribution curve of the cumulative frequency of the proportion of teeth per child according to Thylstrup and Fejerskov index score (TFI) $\geq 1,2,3,4$, and 5, respectively, in 8-to 12-year-old children.

frequent in the upper lateral incisors and permanent first molars. TF3 predominated in the permanent second molars. Comparisons of upper and lower arches showed a moderately strong correlation in severity between arches ( $r$ ho $=0.693, \mathrm{p}<0.001$ ) (Fig. 2).

The associations between the study variables and DF severity (maximum TFI score) among the children included in this study are presented in Table 3. The raw results of the bivariate analysis showed no difference in severity according to age $(p=0.65)$. While higher odds of severity were observed in boys than in girls ( $\mathrm{OR}=1.13$; 95\% CI: $0.49-2.63)$, the difference was not significant. No association was observed between DF severity and the presence of

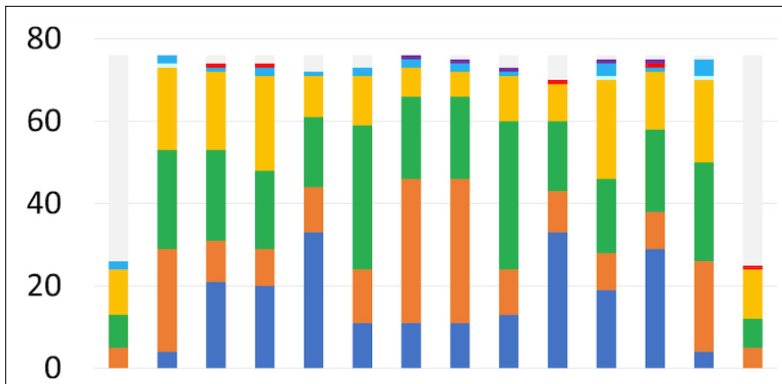

$17161514131211212223242526 \quad 27$

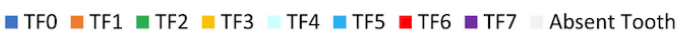
80

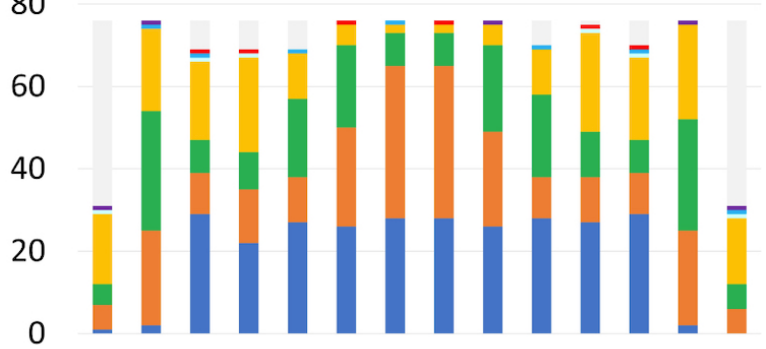

4746454443424131323334353637

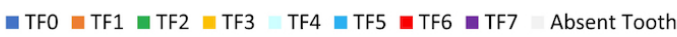

Fig. 2: Distributions of the percentages of teeth with dental fluorosis according to severity and dental arch. Upper and Lower permanent teeth.

$\mathrm{DC}(\mathrm{OR}=1.35 ; 95 \% \mathrm{CI}: 0.56-3.26)$ or $\mathrm{MIH}(\mathrm{OR}$ $=1.39 ; 95 \% \mathrm{CI}: 0.43-4.46)$; however, there were significant differences in children who brushed their teeth three times a day $(\mathrm{OR}=4.05 ; 95 \% \mathrm{CI}$ : 1.22-13.44), children with families with minimumwage income $(\mathrm{OR}=2.95 ; 95 \% \mathrm{CI}: 1.14-6.67)$, and those who used water from the well $(\mathrm{OR}=2.76$; 
Table 3. Correlation of the children's characteristics and dental fluorosis severity. El Cedro, Colombia, 2018.

\begin{tabular}{|c|c|c|c|c|c|}
\hline \multicolumn{2}{|c|}{ Variable } & Raw odds (95\%Cl) & p-value & $\begin{array}{c}\text { Odds Adjusted } \\
(95 \% \mid C)\end{array}$ & p-value \\
\hline \multirow{2}{*}{ Sex } & Female & 1 & & 1 & \\
\hline & Male & $1.13(0.49-2.63)$ & 0.77 & $0.93(0.35-2.43)$ & 0.88 \\
\hline Age & & $0.93(0.69-1.27)$ & 0.65 & & \\
\hline \multirow{2}{*}{ DMFT } & $\mathrm{DMFT}=0$ & 1 & & & \\
\hline & $\mathrm{DMFT} \geq 1$ & $1.35(0.56-3.26)$ & 0.5 & & \\
\hline \multirow{2}{*}{ MIH } & $\mathrm{MIH}=0$ & 1 & & & \\
\hline & $\mathrm{MIH}>0$ & $1.39(0.43-4.46)$ & 0.57 & & \\
\hline \multirow{2}{*}{$\begin{array}{l}\text { Start of brushing } \\
\text { (age, years) }\end{array}$} & $\leq 3$ & 1 & & & \\
\hline & $>3$ & $0.95(0.39-2.29)$ & 0.91 & & \\
\hline \multirow{3}{*}{$\begin{array}{l}\text { Toothbrushing } \\
\text { (times per day) }\end{array}$} & 1 & 1 & & 1 & \\
\hline & 2 & $1.20(0.46-3.12)$ & 0.71 & $0.74(0.21-2.62)$ & 0.65 \\
\hline & 3 & $4.05(1.22-13.44)$ & 0.02 & $2.45(0.61-9.83)$ & 0.2 \\
\hline \multirow{4}{*}{$\begin{array}{c}\text { Toothpaste } \\
\text { amount }\end{array}$} & Minimum & 1 & & 1 & \\
\hline & Smear & $5.12(0.55-47.51)$ & 0.15 & $16.25(0.94-278.21)$ & 0.05 \\
\hline & Pea-sized volume & $7.36(0.82-66.13)$ & 0.08 & $27.42(1.57-477.36)$ & 0.02 \\
\hline & $\begin{array}{c}\text { More than a pea-sized } \\
\text { volume }\end{array}$ & $2.86(0.28-28.97)$ & 0.37 & $12.52(0.61-256.65)$ & 0.1 \\
\hline \multirow{3}{*}{ Toothpaste type } & Children's & 1 & & 1 & \\
\hline & Adult & $0.49(0.20-1.18)$ & 0.11 & $0.29(0.09-0.98)$ & 0.046 \\
\hline & Both & $0.57(0.10-3.34)$ & 0.53 & $0.42(0.05-3.48)$ & 0.42 \\
\hline \multirow{2}{*}{$\begin{array}{l}\text { Swallows tooth- } \\
\text { paste }\end{array}$} & Yes & 1 & & & \\
\hline & No & $0.89(0.36-2.16)$ & 0.79 & & \\
\hline \multirow{3}{*}{ Milk type } & Mother's milk & 1 & & 1 & \\
\hline & Infant formula & $1.55(0.25-9.81)$ & 0.64 & $1.27(0.12-13.10)$ & 0.83 \\
\hline & Cow's milk & $15.39(0.57-418.93)$ & 0.11 & $\begin{array}{c}32.25(0.76- \\
1360.74)\end{array}$ & 0.06 \\
\hline \multirow{2}{*}{ Water source } & Aqueduct, untreated & 1 & & 1 & \\
\hline & Well & $2.76(1.14-6.67)$ & 0.02 & $1.89(0.67-5.36)$ & 0.22 \\
\hline \multirow{4}{*}{ Oven type } & Electric & 1 & & 1 & \\
\hline & Gas & $4.84(0.89-26.45)$ & 0.07 & $2.36(0.33-16.57)$ & 0.38 \\
\hline & Indoor, wood-fired & $9.62(1.58-58.50)$ & 0.01 & $9.34(1.11-78.57)$ & 0.04 \\
\hline & Outdoor, wood-fired & $5.68(1.10-29.33)$ & 0.04 & $4.57(0.73-28.25)$ & 0.1 \\
\hline \multirow{2}{*}{ Family income } & No income & 1 & & 1 & \\
\hline & With minimum income & $2.95(1.14-6.67)$ & 0.03 & $2.83(0.84-9.48)$ & 0.09 \\
\hline
\end{tabular}

95\%CI:1.14-6.67) and an indoor $(\mathrm{OR}=9.62 ;$ food preparation $(\mathrm{OR}=9.34 ; 95 \% \mathrm{CI}$ : $1.11-78.57$, 95\% CI: $1.58-58.50)$ or outdoor $(\mathrm{OR}=5.68 ; 95 \% \mathrm{CI}: \quad \mathrm{p}<0.05)$.

1.10-29.33) wood stove for food preparation ( $\mathrm{p}$ Other perinatal variables, such as low birthweight, $<0.05$ ). When adjusting for multiple regression, only preterm delivery, jaundice, high fever, antibiotics two variables explained DF severity: use of a pea- taken by the child, medications in the mother, $\mathrm{F}$ sized volume of toothpaste $(\mathrm{OR}=27.42 ; 95 \% \mathrm{CI}$ : supplements, and previous information on DF were $1.57-477.36)$ and use of an indoor wood stove for not associated with DF severity $(\mathrm{p} \geq 0.05)$. 


\section{DISCUSSION}

The prevalence of DF in this study population $(98.7 \%)$ was greater than the overall prevalence in Colombia $(62.15 \%)^{24}$; and similar to that in a recent report from another area of southern Colombia, which found that $98.2 \%$ of the children are affected according to TFI criteria ${ }^{25}$.

Almost $100 \%$ of the 8 - to 12 -year-old children in this community had DF, a prevalence higher than those in other countries with fluoridated water, such as the USA $(65.0 \%)^{26}$, in endemic areas due to groundwater such as Kenya $(86.0 \%$ in children under 14 years) ${ }^{27}$, or in rural endemic areas of Brazil with similar climatic conditions to those in the present study $(80.4 \%)^{14}$, Thailand $(18.4 \%)^{16}$, and areas of Nigeria $(11.3 \%$ of children 12 to 15 years old $)^{12}$.

This study classified the children according to the highest value of the 10-degree TFI severity scale ${ }^{23}$. TF3 score (of esthetic concern) was the most frequent, similar to the report by Gevera et al. ${ }^{27}$, but in contrast to Conway et al. ${ }^{28}$, who report a higher prevalence of TF1-TF2 in 7- to 9-year-old children, and Armas-Vega et al. ${ }^{29}$, who report a higher prevalence of TF2 in 10- to 12-year-old children.

Comparisons of DF severity as mild, moderate, or severe should consider both the criteria used to measure DF and subject age. The severity in the present study was higher than in other reports using Dean's criteria. In the USA, moderate and severe DF are observed in $28 \%$ and $2.6 \%$, respectively, of children 12 to 15 years old ${ }^{26}$. In Nigeria, $9.25 \%$ of subjects have very mild, $1.25 \%$ mild, and $0.75 \%$ moderate lesions, with no report of severe DF lesions ${ }^{12}$. In Thailand, $16.15 \%$ and $2.3 \%$ of children 8 to 10 years old present very mild and mild lesions, respectively, with no severe lesions ${ }^{16}$. Bhagavatula et al. ${ }^{4}$ report mainly mild DF, with less than $1 \%$ of subjects having severe DF.

No significant difference was found in the degree of severity between teeth in the upper and lower arches, in contrast to the study by Larsen et al. ${ }^{30}$, who reports variability in the risk period for DF in the upper and lower jaw teeth when examined separately. Although Bhagavatula et al. ${ }^{4}$ did not measure individually, they report similar periods of development for each type of tooth in both arches.

Regarding severity according to tooth type, although the differences were not statistically significant, the findings of the present study show how the time of exposure to accumulated $\mathrm{F}$ and the time of tooth formation and mineralization ${ }^{4}$ can be reflected in the severity. In permanent teeth that erupt early, such as the central incisors of both arches and the lower lateral side (development in the first 4 years of life), there was a predominance of TF1 severity, followed by the upper lateral incisors and the first molar with predominance of TF2 and the second molars and premolars (development at 5-8 years of age) with TF3. However, other factors must be considered, such as the effect of abrasion and brushing on milder lesions and on teeth such as the central incisors that are most exposed, as well as other conditions at the time of clinical examinatio ${ }^{4,31}$.

Although we observed no significant relationship between DF severity and age and sex, among the few studies that have also analyzed the factors associated with severity, our findings are consistent with those published by Pontigo-Loyola et al. ${ }^{13}$, who report no association between severity and sex, and differ from those of Ferreira et al. ${ }^{14}$, who report an association between age and severity $(\mathrm{p}<0.05)$. Other studies present differences in the prevalence of DF according to $\operatorname{sex}^{29}$, while still others report no significant association between DF and age, sex, or socioeconomic status ${ }^{12}$. Considering economic situation, the population of the present study is vulnerable, with only $25.32 \%$ of the families receiving a minimum wage and with 3-7 individuals in $81.58 \%$ of the families. However, with the economic factor in this population treated as a constant, the bivariate analysis showed a correlation with minimum-wage family income (\$247 USD), although the severity was explained by other variables $(p=0.09)$ in the adjusted analysis. Other studies report correlations between socioeconomic status and DF, observing a relationship between higher income and being able to afford to buy toothpaste and other topical fluorides ${ }^{16,28,29,32}$.

Among the statistically significant factors in the present study ( $\mathrm{p}<0.05$ ), the amount of toothpaste (pea-sized volume) used was associated with severity, though the use of more than a pea-sized volume did not present an association, but since its $\mathrm{OR}=12.52$ was high, it was probably not significant because very few children used it $(n=13)$. These results should be interpreted with caution due to their low power. On the other hand, the OR of adult toothpaste seems to be protective. However, an OR below the unit does not always mean protection, 
it could also be more prone to severity and in this population could be associated with other biological variables or biochemical components that were not considered in this study.

Other variables such as starting tooth brushing before the age of 3 years, the frequency of brushing, the type of toothpaste and swallowing the toothpaste during childhood have been related to the prevalence of the DF in other studies ${ }^{4,6,15,26,29}$, although they were not related to the severity of the DF in the current study.

Although $92.11 \%$ of the children in the present study had been breastfed, drinking cow's milk was related to DF severity ( $p=0.06$ in the adjusted analysis). Other reports suggest that while cow's milk has a low F content, the concentration can be increased with the use of infant formulas, processed foods and beverages with fluoridated water ${ }^{26}$, as well as fluorinated salt.

In the present study, a correlation was observed between DF severity and children who received food prepared in an indoor wood stove in their homes. The study population uses fluoridated salt and $59.21 \%$ of families use between 1 and 2 tablespoons of salt when preparing food. The study population lives at an altitude of 40 meters above sea level and there was high prevalence of more severe DF than in populations from other areas at different altitudes. Food preparation and altitude are identified as risk factors in other studies; the latter, especially, may act as a modifying factor for the prevalence and severity of DF, although there is no solid evidence $3,10,13,33,34$. Regarding food preparation, in some parts of China, Fawell et al. ${ }^{2}$ report high fluoride concentrations in indoor air as a result of the use of fluoride-rich coal for drying, curing and cooking food. Other studies report an increase in fluoride concentration when food and water are boiled for a long time and when boiled water is used for reconstituting infant formulas ${ }^{16,35}$. This is often the case in communities that use indoor wood stoves. But again, there is little evidence in this regard.

\section{ACKNOWLEDGMENTS}

The authors would like to thank Dr. Alfonso Escobar for allowing access to the community.

\section{DECLARATION OF CONFLICTING INTERESTS}

The authors declare no potential conflicts of interest regarding the research, authorship, and/or publication of this article
The lack of conclusive evidence for risk factors for DF or its severity is clear, indicating the need for further studies on larger samples ${ }^{15}$ to identify other factors that could modify or multiply the effect or exposure to $\mathrm{F}^{13,26}$. DF was found to be high in 8- to 12 -year-old children in the population of El Cedro. There may be other explanatory factors that have not been studied in the area, including environmental sources, presence of metals or minerals, malnutrition or micronutrient deficiency, genetic factors and other sources of fluoride such as food, snacks and topical fluoride applications.

This study has some limitations. A consequence of the low sample size is that the estimates of some confidence intervals of the OR are broad and the results should therefore be interpreted with caution. We had a low response rate $(35 \%)$. El Cedro is a remote rural community with low accessibility, which explains school absences and the difficulty to obtain informed consent from parents. Moreover, there may be memory bias in parents' answers to the questions on perinatal variables. The strength of the study was that all permanent teeth present were analyzed, individually and separately, in both arches. Despite research obstacles, characterizing DF and associated factors in this kind of community is highly relevant to provide information to support oral health improvements.

\section{CONCLUSION}

The rural community evaluated presented a high frequency of DF. The association between DF severity and the type of tooth provides evidence of the large window of susceptibility and its association with the accumulated exposure to $\mathrm{F}$, with less involvement and lower severity in the lower incisors. The main factors related to DF severity in 8- to 12-year-old children were the use of an indoor wood stove for food preparation and the amount of toothpaste used in childhood.

\section{FUNDING}

This work was supported by the CES University in Medellin Colombia (INV032017008).

\section{CORRESPONDENCE}

Prof. Dr. Fabiano Jeremias

Facultade de Odontologia de Araraquara, Programa de Posgraduación em Ciências Odontológicas.

Universidade Estadual Paulista, São Paulo (Unesp), AraraquaraSP Brasil.

Rua Humaitá, 1680 Araraquara, SP Brasil 14801-903

f.jeremias@unesp.br 


\section{REFERENCES}

1. Ibrahim Y, Abuaffan A, Bjorvatn K. Prevalence of dental fluorosis in Sudanese children from two villages with 0.25 and $2.56 \mathrm{ppm}$ fluoride in the drinking water. Int J Paediatr Dent. 1995;5:223-229.

2. Fawell JK, Bailey K, editors. Fluoride in drinking-water. London; Seattle: IWA Pub; 2006. URL: http://www. who.int/water_sanitation_health/publications/fluoride_ drinking_water_full.pdf

3. Rwenyonyi C, Bjorvatn K, Birkeland J, Haugejorden O. Altitude as a risk indicator of dental fluorosis in children residing in areas with 0.5 and $2.5 \mathrm{mg}$ fluoride per liter in drinking water. Caries Res. 1999;33:267-274.

4. Bhagavatula P, Levy SM, Broffitt B, Weber-Gasparoni K, Warren J. Timing of fluoride intake and dental fluorosis on late-erupting permanent teeth. Community Dent Oral Epidemiol. 2016;44:32-45.

5. Buzalaf MAR, Pessan JP, Honório HM, Ten Cate JM. Mechanisms of action of fluoride for caries control. Monogr Oral Sci. 2011;22:97-114.

6. Celeste R, Luz P. Independent and additive effects of different sources of fluoride and dental fluorosis. Pediatr Dent. 2016;38:233-238.

7. Den Besten P, Li W. Chronic fluoride toxicity: dental fluorosis. Monogr Oral Sci. 2011;22:81-96.

8. Lyaruu DM, Medina JF, Sarvide S, Bervoets TJM, Everts V, Denbesten P, et al. Barrier formation: potential molecular mechanism of enamel fluorosis. J Dent Res. 2014;93:96102.

9. Pérez-Pérez N, Irigoyen-Camacho ME, Boges-Yañez AS. Factors affecting dental fluorosis in low socioeconomic status children in Mexico. Community Dental Health. 2017;34:66-71.

10. Fan Z, Gao Y, Wang W, Gong H, Guo M, Zhao S, et al. Prevalence of brick tea-type fluorosis in the Tibet Autonomous Region. J Epidemiol. 2016;26:57-63.

11. Mahantesh T, Dixit UB, Nayakar RP, Ashwin D, Ramagoni NK, Kamavaram Ellore VP. Prevalence of dental fluorosis and associated risk factors in Bagalkot District, Karnataka, India. Int J Clin Pediatr Dent. 2016;9:256-263.

12. Okoye LO, Ekwueme O-EC, Sote EO, Amaechi BT. Prevalence of dental fluorosis among 12-15-year-old students in Enugu Metropolis, Nigeria. Indian J Dent Res Off Publ Indian Soc Dent res. 2019;30:462-467.

13. Pontigo-Loyola AP, Islas-Márquez A, Loyola-Rodríguez JP, Maupome G, Marquez-Corona ML, Medina-Solis CE. Dental fluorosis in 12- and 15-year-olds at high altitudes in above-optimal fluoridated in Mexico. J Public Health Dent. 2008; 68:163-166.

14. Ferreira EF, Vargas AMD, Castilho LS, Velásquez LNM, Fantinel LM, Abreu MHNG. Factors associated to endemic dental fluorosis in Brazilian rural communities. Int $\mathrm{J}$ Environ Res Public Health. 2010;7:3115-3128.

15. Azevedo MS, Goettems ML, Torriani DD, Demarco FF. Factors associated with dental fluorosis in school children in southern Brazil: a cross-sectional study. Braz Oral Res. 2014; 28:S1806-83242014000100220.

16. Nakornchai S, Hopattaraput P, Vichayanrat T. Prevalence, severity and factors associated with dental fluorosis among children aged 8-10 years in Bangkok, Thailand. Southeast Asian JTrop Med Public Health. 2016; 47:1105-1111.
17. European Commission, Directorate General for Health \& Consumers, SCHER. Critical review of any new evidence on the hazard profile, health effects, and human exposure to fluoride and the fluoridating agents of drinking water. URL: https://ec.europa.eu/health/scientific_committees/ environmental_risks/docs/scher_o_139.pdf

18. Molina-Frechero N, Gaona E, Angulo M, Sánchez Pérez L, González González R, Nevarez Rascón M, Bologna-M. Fluoride Exposure Effects and Dental Fluorosis in Children in Mexico City. Medical Science Monitor 2015;21:366470 .

19. Thylstrup A, Fejerskov O. Clinical appearance of dental fluorosis in permanent teeth in relation to histological changes. Community Dent Oral Epidemiol. 1978;6:315328.

20. Weerheijm K, Duggal M, Mejàre I, Papagiannoulis L, Koch $\mathrm{G}$, Marten L, et al. Judgement criteria for molar incisor hypomineralisation (MIH) in epidemiologic studies: a summary of the European meeting on MIH held in Athens, 2003. Eur J Paediatr Dent. 2003;4:110-113.

21. World Health Organization (WHO). Oral Health Surveys. Basic Methods. France: WHO Library Cataloguing-inPublication Data; 2013.

22. Seow WK. Clinical diagnosis of enamel defects: pitfalls and practical guidelines. International Dental Journal 1997;47:173-182.

23. Fejerskov O, Manji F, Baelum V, Møller IJ. Dental fluorosis a handbook for health workers. Copenhagen: Munksgaard; 1988.p. 123 .

24. Colombia. Ministerio de Salud y Protección Social. IV estudio nacional de salud bucal ENSAB IV: situación de salud bucal URL: https://www.minsalud.gov.co/sites/ $\mathrm{rid} /$ Lists/BibliotecaDigital/RIDE/VS/PP/ENSAB-IVSituacion-Bucal-Actual.pdf.

25. Martignon S, Opazo-Gutierrez MO, Velasquez-Riaño M, Orjuela-Osorio I, Avila V, Martinez-Mier E, et al. Geochemical characterization of fluoride in water; table salt, active sediment, rock and soil samples, and its possible relationship with the prevalence of enamel fluorosis in children in four municipalities of the department of Huila (Colombia). Environmental Monitoring and Assessment 2017;89:264.

26. Neurath C, Limeback H, Osmunson B, Connett M, Kanter V, Wells C. Dental Fluorosis Trends in US Oral Health Surveys: 1986 to 2012. JDR Clin Transl Res. 2019;4:298308.

27. Gevera P, Mouri H, Maronga G. Occurrence of fluorosis in a population living in a high-fluoride groundwater área: Nakuru area in the Central Kenyan Rift Valley. Environ Geochem Health 2019;41:829-840.

28. Conway DI, MacPherson LMD, Stephen KW, Gilmour W, Petersson LG. Prevalence of dental fluorosis in children from non-water-fluoridated Halmstad, Sweden: fluoride toothpaste uses in infancy. Acta Odontol Scand. 2005;63:5663.

29. Armas-Vega A, Gonzalez-Martinez F, River-Martinez M, Mayorga-Solórzano M, Banderas-Benítez V, GuevaraCabrera O. Factors associated with fluorosis in three zones of Ecuador. J Clin Expl Dent. 2019;11:42-48.

30. Larsen MJ, Richards A, Fejerskov O. Development of dental 
fluorosis according to age at start of fluoride administration. Caries Res. 1985;19:519-527.

31. Escobar Rojas A, Bullio Fragelli CM, Girotto Bussaneli D, Patrícia Cavalheiro J, Santos-Pinto L, Restrepo M, et al. Clinical aspects of dental fluorosis according to histological features: a Thylstrup Fejerskov index review. CES Odontol. 2017; 30:41-50.

32. Angulo M, Cuitiño E, Molina-Frechero N, Emilson CG. The association between the prevalence of dental fluorosis and the socio-economic status and area of residence of 12-yearold students in Uruguay. Acta Odontol Scand. 2019;78:2630 .
33. Martínez-Mier EA, Soto-Rojas AE, Ureña-Cirett JL, Katza BP, Stookey GK, Dunipace AJ, et al. Dental fluorosis and altitude: a preliminary study. Oral Health Prev Dent. 2004;2:39-48.

34. Akosu TJ, Zoakah AI, Chirdan OA. The prevalence and severity of dental fluorosis in the high and low altitude parts of Central Plateau, Nigeria. Community Dental Health. 2009;26:138-42.

35. Grimaldo M, Borja-Aburto VH, Ramírez AL, Ponce M, Rosas M, Díaz-Barriga F. Endemic fluorosis in San-LuisPotosi, Mexico. Identification of risk factors associated with human exposure to fluoride. Environ Res. 1995;68:25-30. 